\title{
A experiência da soropositividade para grávidas com HIV/AIDS: preconceito, dor, trauma e sofrimento pela descoberta
}

\author{
Pregnant women's experience of being seropositive for HIV/AIDS: prejudice, pain, trauma \\ and suffering at the discovery
}

La experiencia de la embarazada seropositiva para el VIH / SIDA: prejuicio, dolor, trauma y sufrimiento al tomar conocimiento

\author{
Ana Paula Dantas Silva Medeiros'; Verbena Santos AraújoII; Marina Nascimento de Moraes ${ }^{I I I}$; \\ Sandra Aparecida de Almeida ${ }^{I V}$; Jordana Nogueira de Almeida ; Maria Djair Dias ${ }^{V I}$
}

\begin{abstract}
RESUMO: Pesquisa qualitativa, com o objetivo de conhecer a experiência de vida de mulheres gestantes/puérperas a partir da descoberta da soropositividade para o vírus da Imunodeficiência Humana (HIV) e a Síndrome da Imunodeficiência Adquirida (AIDS). Estudo realizado no Hospital Universitário Lauro Wanderley, na cidade de João Pessoa, Paraíba. O material empírico foi produzido a partir das entrevistas realizadas com 12 participantes do estudo, no período de julho a setembro de 2012, utilizando-se a História Oral Testemunhal e discutido por meio da análise temática interpretativa. Como resultado, observou-se que as mulheres pesquisadas expressaram sentimentos conflitantes, como morte e vida, alegria e tristeza, medo e incerteza. Conclui-se que este estudo torna-se de grande importância por ressaltar as experiências de vida das gestantes e puérperas soropositivas para HIV/AIDS, buscando ampliar a discussão quanto às formas de enfrentamento utilizadas por essas mulheres frente à descoberta da patologia. Palavras-Chave: Síndrome de imunodeficiência adquirida; período pós-parto; saúde da mulher; história oral.
\end{abstract}

ABSTRACT: This qualitative study, which aimed to learn the life experiences of pregnant and postpartum women following their discovering themselves seropositive for the human immunodeficiency virus (HIV) and Acquired Immune Deficiency Syndrome (AIDS), was conducted at the Lauro Wanderley University Hospital in João Pessoa, Paraíba. The empirical data were obtained from interviews of twelve study participants, from July to September 2012, using the Testimonial Oral History approach, and were discussed through interpretive thematic analysis. As a result, it was observed that the women surveyed expressed conflicting feelings, such as life and death, joy and sorrow, fear and uncertainty. It was concluded that this study is of great importance, because it brings out the life experiences of pregnant women and mothers who are seropositive for HIV/ AIDS, with a view to fostering discussion of ways these women cope after discovering the disease.

Keywords: Acquired immunodeficiency syndrome; postpartum period; women's health; oral history.

RESUMEN: Investigación cualitativa cuyo objetivo es conocer la experiencia de vida de las mujeres embarazadas/puérperas desde el descubrimiento de la seropositividad para el Virus de la inmunodeficiencia humana (VIH) y el Síndrome de Inmunodeficiencia Adquirida (SIDA). Estudio realizado en el Hospital Universitario Lauro Wanderley en la ciudad de João Pessoa, Paraíba. Los datos empíricos se han obtenido por medio de entrevistas a doce participantes del estudio, de julio a septiembre de 2012, utilizando la Historia Oral Testimonial, y se han discutido a través del análisis temático interpretativo. Como resultado, se ha observado que las mujeres encuestadas han expresado sentimientos conflictivos, como vida y muerte, alegría y tristeza, miedo e incertidumbre. Llegamos a la conclusión de que este estudio se vuelve muy importante puesto que pone de relieve las experiencias de vida de las mujeres embarazadas y puérperas seropositivas para VIH / SIDA, buscando profundizar la discusión sobre las formas de enfrentamiento utilizadas por estas mujeres ante el descubrimiento de la enfermedad.

Palabras Clave: Síndrome de inmunodeficiencia adquirida; período de postparto; salud de la mujer; historia oral.

\section{INTRODUÇÃO}

A velocidade com que a Síndrome da Imunodeficiência Adquirida (AIDS), causada pelo Vírus da Imunodeficiência Humana (HIV), se disseminou no mundo, a severidade com que os pacientes são atingidos e o potencial de letalidade da doença preocupam não só pessoas diretamente afetadas, mas todas as camadas da

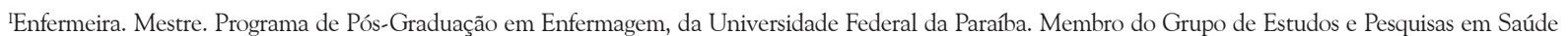
Mental Comunitária. João Pessoa, Paraíba, Brasil. E-mail: ap-dantas@hotmail.com.

I"Enfermeira. Mestre e Doutoranda. Programa de Pós-Graduação em Enfermagem, da Universidade Federal da Paraíba. Docente da Escola de Enfermagem de Natal/ UFRN. Membro do Grupo de Estudos e Pesquisas em Saúde Mental Comunitária. João Pessoa, Paraíba, Brasil. E-mail: verbena.bio.enf@hotmail.com.

IIIEnfermeira. Mestre. Programa de Pós-Graduação em Enfermagem, da Universidade Federal da Paraíba. Membro do Grupo de Estudos e Pesquisas em Saúde Mental Comunitária. João Pessoa, Paraíba, Brasil.E-mail: ninamoraes@@hotmail.com.

IVEnfermeira. Doutora. Professora do Programa de Pós-Graduação em Enfermagem, da Universidade Federal da Paraíba. Membro do Núcleo de Estudo em HIV/ AIDS, Saúde e Sexualidade. João Pessoa, Paraíba, Brasil. E-mail: sandraalmeida124@gmail.com.

vEnfermeira. Doutora em Enfermagem e Saúde Pública. Professora do Programa de Pós-Graduação em Enfermagem, da Universidade Federal da Paraíba. Líder do Núcleo de Estudo em HIV/AIDS, Saúde e Sexualidade. João Pessoa, Paraíba, Brasil. E-mail: jalnogueira31@gmail.com.

"Enfermeira. Doutora em Enfermagem. Professora Associado I do Programa de Pós-Graduação em Enfermagem da Universidade Federal da Paraíba e Vice-líder do Grupo de Estudos em Saúde Mental e Comunitária. João Pessoa, Paraíba, Brasil. E-mail: mariadjair@yahoo.com.br. 
sociedade. Decerto, o preconceito surge desde o início da epidemia, o que remontava a doença a grupos marginalizados da sociedade. Essa tentativa de marginalização pode ser entendida como parte da heteronormatização da sociedade e do foco na família nuclear ${ }^{1}$.

Sendo assim, abordar a temática AIDS envolve questões complexas, especificamente em mulheres, pois há confrontamento de sentimentos muito particulares como valores, medo, casamento, maternidade, as relações de gênero e a sexualidade que permeia toda a epidemia ${ }^{1}$.

O medo acompanha essas mulheres de forma permanente, fazendo-as vítimas do esquecimento e da invisibilidade, exigindo-lhes uma atenção constante, cotidiana e autovigilante para que não sejam discriminadas nos ambientes os quais elas vivem. Sentir-se culpada, com medo, estigmatizada e ter necessidade de se esconder são sentimentos que certamente não contribuem para uma melhor saúde psicológica dessas mulheres com soropositividade para o vírus HIV/ AIDS, dificultando o enfrentamento à doença ${ }^{2}$.

A gestação de uma mulher que vive com o HIV/ AIDS transcende as questões puramente técnicas. Sua ocorrência não é vinculada, apenas, ao temor pelo risco de infecção ao bebê, mas pelo risco social que simbolicamente está associado à reprodução na presença do vírus. $\mathrm{O}$ medo de enfrentar a sociedade e vivenciar o preconceito as tornam mais suscetíveis a uma série de problemas, pois a gravidez representa um momento de grandes mudanças na vida da mulher e requer cuidados especiais.

Com base nesse panorama, esta pesquisa teve como objetivo conhecer a experiência de vida de mulheres gestantes/puérperas a partir da descoberta da situação de soropositividade para HIV/AIDS.

\section{REVISÃO DE LITERATURA}

perfil epidemiológico da AIDS, desde sua descoberta, vem sofrendo transformações quanto a sua forma de disseminação ${ }^{3}$, descaracterizando-a como uma doença restrita a grupos específicos. Tal modificação ocorreu em função da multiplicidade de fatores que modulam a epidemia, o que não lhe conferiu uniformidade, já que sua ocorrência aumentou entre homens heterossexuais, mulheres, populações socialmente mais vulneráveis, idosos e jovens, desencadeando processo denominado como pauperização da epidemia ${ }^{4}$.

Analisando-se o acumulado dos casos de AIDS em gestantes notificados no Brasil até o ano de 2014, houve 84. 558 casos, sendo os mais representativos compreendidos nas faixas etárias de 20 a 24 anos, com $24.172(28,9 \%)$, e de 25 a 29 anos, com 22.732 $(27,2 \%)$. Em relação à escolaridade, nota-se que $27.122(39,9 \%)$ casos não completaram o ensino fundamental e 11.958 (17,6\%) têm o nível médio incompleto 5 .
$\mathrm{O}$ aumento de casos de mulheres vivendo com HIV/AIDS possui implicações na fase gestacional e o incremento da taxa de transmissão vertical, expondo a fragilidade e dificuldade de operacionalização de ações de prevenção e adequado manejo do agravo nos diversos contextos sanitários.

\section{Metodologia}

Para compreender o objetivo desta investigação, optou-se por estudar o fenômeno com base nos pressupostos da História Oral (HO) adotados por Bom Meihy ${ }^{6}$. Esse caminho foi escolhido por ser capaz de apreender o significado das experiências vivenciadas, expressas por meio dos depoimentos, sendo um processo sistematizado e planejado previamente em um projeto em que a oralidade é registrada e transportada para o meio escrito, possibilitando realizar análises do contexto social e individual, que deverão ser interligados e interdependentes $^{7}$. A opção por se trabalhar com a $\mathrm{HO}$ testemunhal, em uma de suas interfaces, ocorreu em função de sua aplicabilidade em vivências dramáticas, o que se observa nos depoimentos das mulheres participantes do estudo, perante a temática adotada.

Foi escolhido como cenário desta investigação o Hospital Universitário Lauro Wanderley (HULW) na cidade de João Pessoa, Paraíba, por se tratar de uma unidade de referência no tratamento e acompanhamento de gestantes e puérperas que vivem com o vírus HIV/AIDS.

Respeitando os pressupostos da $\mathrm{HO}$, a comunidade de destino foi constituída por mulheres soropositivas para HIV/AIDS inscritas no Serviço Ambulatorial Especializado - Materno Infantil (SAE/MI) do HULW. A colônia selecionada foi formada pelas mulheres gestantes e puérperas e a rede foi composta por mulheres soropositivas para HIV/AIDS, identificadas pela letra inicial do seu nome civil, seguida do número referente à ordem de realização da entrevista. As entrevistas foram realizadas nos meses de julho a setembro de 2012, com um total de 12 participantes.

A discussão e análise do material empírico foram subsidiadas à luz técnica da análise de conteúdo de Bardin $^{8}$, que consiste na apreciação qualitativa de conteúdo, conceituada como um conjunto de técnicas de análise de comunicações e que tem como objetivo ultrapassar as incertezas e enriquecer a leitura dos dados coletados. A sua finalidade é compreender criticamente o sentido das comunicações, seu conteúdo manifesto ou latente, as significações explícitas ou ocultas ${ }^{8}$.

Como etapas de análise, foram realizadas a transcrição e a leitura de todo material empírico produzido, a transcrição e a construção das unidades de registro e, a partir dessas, das unidades de contexto. Em seguida, definiram-se os eixos temáticos e a interpretação seguida da categorização das informações, tendo como 
resultado desse processo o seguinte eixo temático: Experiência da soropositividade para HIV/AIDS: a dor, o trauma e o sofrimento da descoberta.

Este estudo atendeu aos requisitos propostos pela Resolução no 466/2012 do Conselho Nacional de Saúde ${ }^{9}$, que dispõe sobre as normas e diretrizes regulamentadoras da pesquisa envolvendo seres humanos. Antes da realização, o projeto da pesquisa foi cadastrado na Plataforma Brasil do Ministério da Saúde e aprovado pelo Comitê de Ética e Pesquisa do Hospital Universitário Lauro Wanderley, recebendo o parecer favorável segundo o CAAE 02367612.4.0000.5183. $\mathrm{E}$, atestando a veracidade dos fatos, todas as colaboradoras deste estudo assinaram a Carta de Cessão e o Termo de Consentimento Livre e Esclarecido.

\section{Resultados e Discussão}

\section{Experiência da soropositividade para HIV/AIDS: a dor, o trauma e o sofrimento da descoberta}

Os acontecimentos que marcaram a história da epidemia evocam a morte, vivência que o sujeito desconhece ou conhece mediante a experiência do outro, não sendo um registro do que se passou consigo mesmo. Considerando a impossibilidade de se imaginar a própria morte, sempre que se tenta fazê-lo, podese perceber que ainda o sujeito está presente como espectador . Dessa maneira, infere-se que a angústia presente nas mulheres com diagnóstico positivo para o vírus HIV tem relação não só pelo estado em que se encontram, mas pela situação da própria doença. Vale ressaltar que nunca se está suficientemente pronto para aceitar a morte, mesmo considerando sua inevitabilidade ${ }^{10}$.

No inconsciente, a imortalidade é algo que impossibilita o ser humano de pensar e de falar sobre a morte, uma experiência pela qual nunca passou, colocando-o frente a suas próprias limitações, o que desafia a sua onipotência, porém, diante de algo desconhecido, é impossível não imaginar que esse fenômeno natural chegará mais rápido ${ }^{11}$. Os depoimentos a seguir abordam o pensamento de algumas mulheres no momento em que descobriram a soropositividade e se viram diante desse desafio:

[...] eu queria me matar, só não fiz porque estava grávida. (J1)

[...] queria morrer, eu pensei que a partir daquele momento nada mais teria sentido [...] . (R2)

O paradoxo vida e morte que passa a fazer parte da vivência das mulheres que convivem com o HIV geram enorme angústia, uma vez que a representação da mãe, mulher que dá a vida, opõe-se àquela de mulher perigosa, gerando enorme conflito na mente do indivíduo em relação aos papéis esperados socialmente ${ }^{12}$.
$\mathrm{Na} \mathrm{HO}$, o Tom Vital corresponde às frases que servem de epígrafe para a leitura da entrevista. Dessa maneira, algumas colaboradoras relatam a exteriorização da nova realidade frente ao medo, o desespero e ao trauma, a partir do seu Tom Vital, como se observa a seguir:

\section{[...] o mundo acabou [...]. (I3)}

A depoente anteriormente citada tinha conhecimento do seu diagnóstico há cinco anos e revelou que foi muito difícil descobrir a presença do vírus em seu corpo. Na maternidade, foi realizado o teste rápido anti-HIV, sendo diagnosticado positivo. A paciente relatou que o nascimento do seu filho passou a não ter mais importância para ela. Suas ações depressivas, temor e o sofrimento diante essa nova descoberta fizeram com que o seu tom vital fosse comparado a uma grande catástrofe emocional.

O trauma psicológico é resultante de uma situação experimentada, testemunhada ou confrontada pelo indivíduo que sofreu ameaça à vida ou à integridade física e/ou psicológica de si próprio ou de pessoas a ele ligadas. Quando se projeta ações tidas como traumas, as pessoas tentam manter o controle de ameaças internas. Entretanto, essa perspectiva diante da doença, associada ao fato da infecção pelo vírus do HIV/AIDS ser potencialmente fatal, dificulta a compreensão da enfermidade pela maior parte da sociedade ${ }^{13}$.

Aprender a expressar o que se está sentindo nesse momento é algo muito difícil para pessoas que estão com medo, ou passando por algum processo traumático. A palavra nem sempre é o meio mais interpretativo para apreender a angústia de certos indivíduos, sendo importante saber que existe diferença no modo de pensar, falar e se expressar. Quando as pessoas se deparam com alguma informação inesperada e inaceitável, traumatizam o momento e pensam negativamente.

O trauma, em sua raiz etimológica grega, significa lesão causada por um agente externo, porém esse conceito migrou após os estudos de Freud, no ano de 1895, sendo hoje ligado a algo interno causado por meio externo. No entanto, Freud associou a internalidade à externalidade como agente causador, o que retratam os fragmentos de falas pela ocasião da descoberta da soropositividade para HIV/AIDS ${ }^{13}$.

Entre os componentes do aconselhamento, o apoio emocional é fundamental para contribuir no enfrentamento das questões emergentes após a descoberta da soropositividade, especialmente do medo da morte e expectativa desastrosa ${ }^{14}$.

Observa-se que a convivência com o HIV implica para a mulher vivenciar sentimentos adversos, os quais podem ser traduzidos por estados individuais decorrentes do grande abalo emocional causado pelo enfrentamento ao vírus. Tais sentimentos refletem a 
impossibilidade de esquecimento da soropositividade na medida em que a doença traz em si uma relevante carga de estigmatização, identificada na falta de oportunidade de trabalho, arrependimento, afastamento de amigos, discriminação familiar, acometimento de doenças que acarretam limitantes sequelas físicas, além do sentimento de fragilidade ante o preconceito, como se observa nas citações seguintes:

Até hoje ainda é difícil. Eu tinha e tenho medo do preconceito, as pessoas logo pensariam que eu errei, porque as pessoas ligam o diagnóstico de AIDS com prostituição, iam pensar que eu era prostituta! (M4)

[...] um dia decidi contar para uma colega minha, só que depois eu disse que era mentira, para saber qual seria a reação, ela nunca mais foi a mesma. Mesmo eu dizendo que era mentira. (R2)

O fato de saber ser portadora de doença letal gera uma diversidade de sentimentos angustiantes, como o medo, a vergonha, a ansiedade e a depressão. $\mathrm{E}$ associados a todas essas emoções, vivenciam o estigma, o preconceito, o isolamento e, muitas vezes, o abandono ${ }^{15}$.

O estigma e a discriminação são artifícios de desvalorização dos sujeitos que lançam injustiças sociais e fortificam aquelas já existentes. Ter uma vida sem estigmas e de qualquer tipo de discriminação é um direito humano básico e que deve ser respeitado. Sendo assim, ser portador de HIV/AIDS não pode e não deve ser considerado motivo para desrespeitar esse direito ${ }^{16}$.

Observa-se, nos relatos a seguir, que a discriminação começa a partir da própria família e se estende pela sociedade em geral. Por esse motivo, o medo do preconceito, da solidão e do abandono acompanham essas mulheres após o resultado positivo pra o vírus da HIV.

[...] minha mãe tem racismo [...], imagina com isso, quem conhece ela sabe, então se eu contasse aquele diagnóstico ela não ia me aceitar, ninguém ia me aceitar [...]. (F5)

[...] Eu prefiro não contar, minha família é muito preconceituosa, tenho medo de ser rejeitada, as pessoas têm muito preconceito com quem é soropositiva, trata a pessoa como um 'cachorro'. (I3)

A família caracteriza-se como o núcleo da sociedade; é nela que as pessoas nascem, crescem e adquirem valores que servirão de base para a vida presente e futura. A importância da rede de apoio familiar para as gestantes é algo retratado não somente pela sabedoria popular. A participação do pai na vida familiar, dos avós paternos e, em especial, dos maternos nos cuidados com a gestante/puérpera e o bebê, bem como o apoio psicológico recebido, foram considerados de grande relevância em diferentes estudos ${ }^{17,18}$.

A parte da epidemia da aids considerada como a mais explosiva, deletéria e danosa seria a das respostas sociais, culturais, econômicas e políticas, que têm se caracterizado por níveis excepcionalmente altos de estigma, discriminação e também de negação coletiva ${ }^{18}$, como reforça o tom vital da colaboradora a seguir:

\section{[...] eu não acredito [...]. (F5)}

Uma estratégia bastante mencionada pelas participantes do estudo foi a negação, ou seja, uma maneira de evitar pensar no problema da soropositividade e passar a pensar somente no bebê. A sensação de incapacidade e insegurança amenizaram quando tais gestantes compartilharam com os familiares o diagnóstico e, principalmente, quando encontram o apoio necessário.

A negação é um mecanismo de defesa operado inconscientemente, usado para resolução de um conflito emocional e para o alívio da ansiedade. Entretanto, essa negação ocasiona o indeferimento de alguns elementos importantes para a vida cotidiana, visto que os sentimentos negados podem ser pensamentos, desejos, necessidades, ou, até mesmo, realidades ${ }^{19}$.

Por meio dos depoimentos das colaboradoras, observa-se que o medo de que a patologia ocasione a sua morte esteve presente na maioria dos discursos, assim como a não aceitação do diagnóstico pelos companheiros, mostrando que o grau de autonomia e flexibilidade no desempenho dos papéis de gênero se mantém diretamente proporcional ao grau de decisão e à possibilidade de elaboração da crise. Apesar de todos os avanços no tratamento da doença nos últimos nos, se descobrir infectado pelo HIV continua gerando um grande impacto emocional e uma situação de vulnerabilidade ${ }^{20}$.

No momento eu achava que logo eu iria morrer [...]. (M4)

Foi muito difícil, tive vontade de me matar [...]. (I3)

Entre as principais sequelas psicológicas causadas pelo impacto de experiências traumáticas estão os medos específicos, que se tornam muito comuns quando atingem traumas psicológicos, comprometendo a qualidade de vida do indivíduo. A este processo, denomina-se Transtorno de Estresse PósTraumático (TEPT), que pode emergir de eventos como parto, aborto, descobrimento da AIDS, câncer, entre outros ${ }^{13}$.

O preconceito e a discriminação existentes contra grupos da população já estigmatizados e discriminados devido à sua raça, sexo e/ou orientação sexual, a irresponsabilidade e as notícias tendenciosas da imprensa relacionadas com o HIV/AIDS despertam inúmeras opiniões preconceituosas e pré-concebidas que ocasionam negativismo e a não aceitação das pessoas portadoras dessa doença. Esses temas tornam-se, então, presentes na vida da mulher com soropositividade para o HIV, o que poderá interferir na forma como vivenciará a maternidade. 
Esse sentimento de medo de ser excluída ou estigmatizada foi bastante evidente nos discursos das colaboradoras, que não hesitaram em testemunhar:

[...] tenho medo mesmo é das pessoas, ninguém ia me aceitar, iam me apontar na rua, a fama na rua ia ser maior, todo mundo ia me destratar. (I3)

[...] todo mundo é preconceituoso, se contar, elas saem de perto [...]. (AC6)

Ainda caracterizado como um evento catastrófico na vida das pessoas, o diagnóstico da aids é permeado por representações associadas à morte rápida e deterioração. Acresce-se a essas questões o fato de ainda não haver cura e da medicação não garantir uma vida sem o vírus ${ }^{21}$, apesar de melhorar a qualidade de vida das pessoas.

Em confronto ao impacto de algo novo e, principalmente, desconhecido e que causa medo, a tendência das pessoas é o temor ao inesperado, associando às reações do impacto da descoberta as definições de quem realmente são. Dito de outro modo, o fato da mulher estar infectada pelo HIV/AIDS fará com que ela se sinta diferente e, portanto, não merecedora de respeito, dignidade e confiança. Através da observação e do testemunho de vida de cada gestante e de cada puérpera, pode-se perceber como as formas de sofrimento se intercalam entre choros, silêncios, tremores na fala, negação da resposta que lhe lembrava sofrimento e até risos. Foram formas de demonstrar a dor, o trauma e as memórias que pertenciam individualmente a cada uma, mas que refletiam igualmente em todas. Semelhanças a formas distintas, belezas diferentes, dificuldades na vida, lutas e vitórias, filhos: o desejo de ser mãe falava sempre mais alto.

\section{CONCLUSÃo}

Verificou-se que o enfrentamento do diagnóstico de soropositividade gera grande impacto na vida das mulheres e que as mudanças advindas a partir dessa notícia possibilitam o surgimento de sentimentos distintos, que afloram em diferentes intensidades e manifestações, tornando-os ainda mais presentes quando associados à ideia de gestação, gerando traumas, dores, medos, preconceitos e discriminações.

Tal situação abre um leque de possibilidades para a atuação profissional da área da saúde e em específico para a enfermagem. Assim, considera-se importante a implementação de ações interdisciplinares que possam sustentar uma proposta de intervenção prática e responsável no que se refere ao cuidado dessas mulheres, mães, filhos e familiares, com enfoque no cuidado enquanto um pressuposto ético e de valorização da vida.

Por se tratar de um tema ainda polêmico e estigmatizante, o estudo apresentou limitações no tocante à adesão de um número maior de mulheres à proposta, visto que o medo e a incerteza podem ter contribuído para restringir o quantitativo de entrevistadas, porém, como se trata de uma pesquisa qualitativa, não há necessidade de um universo maior para realizá-la.

Conclui-se que este estudo é de grande importância por ressaltar as experiências de vida das gestantes e puérperas soropositivas para HIV/AIDS, pois valoriza as formas de enfrentamento utilizadas por essas mulheres frente à descoberta da patologia. Assim, espera-se que a abordagem apresentada possa vislumbrar novos modos de enxergar a problemática e, quiçá, fazer com que a sociedade reveja posicionamentos.

\section{REFERÊNCIAS}

1.Julião TC, Aguiar CN, Araújo FM, Silva RM. O cotidiano de mulheres e a prevenção da AIDS. In: Damasceno MMC, Araújo TL, Fernandes AFC. Transtornos vitais no fim do século XX: diabetes mellitus, distúrbios cardiovasculares, câncer, AIDS, tuberculose e hanseníase. Fortaleza (CE): FCPC; 1999.

2.Ministério da Saúde (Br). Secretaria de Vigilância de Saúde. Programa Nacional de DST e Aids. PCAP: Pesquisa de Conhecimentos, Atitudes e Práticas na População Brasileira. Brasília (DF): Editora MS; 2010. 3.Szwarwald CL. Estimativa do número de pessoas de 15 a 49 anos infectadas pelo HIV, Brasil, 2004. Boletim Epidemiológico AIDS. 2006; 3: 11-5.

4.Parker R. Na contramão da AIDS: sexualidade, intervenção, política. Rio de Janeiro: ABIA; 2002.

5.Ministério da Saúde (Br), Secretaria de Vigilância em Saúde, Departamento de DST, Aids e Hepatites Virais. Boletim epidemiológico HIV/Aids. Ano III. Brasília (DF): Ministério da Saúde; 2014.

6.Bom Meihy JCS, Ribeiro S.L.S. Guia prático de história oral: para empresas, universidades, comunidades, famílias. São Paulo: Contexto; 2011.

7.Bom Meihy JCS, Holanda F. História Oral: como fazer e como pensar. São Paulo: Contexto; 2007.

8.Bardin L. Análise de conteúdo. Lisboa (Pt): Edições $70 ; 2009$.

9.Conselho Nacional de Saúde (Br). Resolução no 466, de 12 de dezembro de 2012. Brasília (DF); CNS; 2012. 10.Freud S. Reflexões para os tempos de guerra e morte. Rio de Janeiro: Imago; 1975.

11.Veras JF. Adoecimento psíquico em mulheres portadoras do vírus HIV: um desafio para a clínica contemporânea. Psicologia Ciência e Profissão. 2007; 27: 266-75. 12.Cotovio VV. HIV/Sida: da Prevenção ao Apoio. Revista Análise Psicológica (São Paulo). 1992; 1: 90.

13.Peres J. Trauma e superação: o que a psicologia e a neurociência e a ensinam. São Paulo: Roca; 2009.

14.Araújo MAL, Queiroz FPA, Melo SP, Silveira CB, Silva RM. Gestantes portadoras do HIV: enfrentamento e percepção de uma nova realidade. Cienc Cuid Saude. 2008; 7: 216-23.

15.Carvalho CML, Galvão MTG. Enfrentamento da Aids entre mulheres infectadas em Fortaleza - CE. Rev esc enferm USP. 2008; 42: 90-7.

16.Medeiros APDS. Mulheres gestantes e puérperas soropositividade para HIV/Aids: História Oral Testemunhal 
[dissertação de mestrado]. João Pessoa (PB): Universidade Federal da Paraíba; 2012.

17.Vieira AM, Padilha MICS. O cotidiano das famílias que convivem com o HIV: um relato de experiência. Esc Anna Nery 2004; 11: 351-7.

18.Parker R, Aggleton P. Estigma, discriminação e AIDS. Rio de Janeiro: Associação Brasileira Interdisciplinar em AIDS; 2006.
19. Townsen MC. Enfermagem psiquiátrica conceitos de cuidados. $3^{\mathrm{a}} \mathrm{ed}$. Rio de Janeiro: Guanabara Koogan; 2002. 20.Cardoso AL, Marcon SS, Waidmani MAP. O. Impacto da descoberta da Aids. Rev enferm UERJ. 2008; 16: 326-32.

21.Duffy L. Suffering, shame, and silence: the stigma of HIV/Aids. J Ass Nurs Aids Care. 2005; 16(1): 13-20. 